\title{
Erratum to: Microsatellite-based evidences of genetic bottlenecks in the cryptic species "Andrographis paniculata Nees": a potential anticancer agent
}

\author{
Alireza Valdiani · Arash Javanmard • \\ Daryush Talei $\cdot$ Soon Guan Tan $\cdot$ Sonia Nikzad $\cdot$ \\ Mihdzar Abdul Kadir · Siti Nor Akmar Abdullah
}

Published online: 21 November 2012

(C) Springer Science+Business Media Dordrecht 2012

\section{Erratum to: Mol Biol Rep}

DOI 10.1007/s11033-012-2231-6

This erratum is published as there were discrepancies in the original publication.

1. Figure 2 (legend): the primers 16, 17, 18 and 19 should be read without " $\mathrm{N}$ ".

The online version of the original article can be found under doi:10.1007/s11033-012-2231-6.

\section{A. Valdiani $(\square)$}

Department of Biochemistry, Faculty of Biotechnology and Biomolecular Sciences, Universiti Putra Malaysia (UPM), 43400 Serdang, Selangor, Malaysia

e-mail: alireza.valdiani@gmail.com

A. Javanmard

Agriculture Biotechnology Research Institute of Iran (ABRII),

Karaj, Iran

D. Talei

Medicinal Plant Research Center, Shahed University, Tehran, Iran

S. G. Tan · S. Nikzad

Department of Cell and Molecular Biology,

Faculty of Biotechnology and Biomolecular Sciences,

Universiti Putra Malaysia (UPM), 43400 Serdang, Selangor,

Malaysia

M. A. Kadir $(\varangle)$. S. N. A. Abdullah

Department of Agriculture Technology, Faculty of Agriculture,

Universiti Putra Malaysia (UPM), 43400 Serdang, Selangor,

Malaysia

e-mail: mihdzar@gmail.com
2. Last page (before the references), "Pfu Taq" should be changed to "Pfu" (without "Taq"). This mistake happened twice. The second Pfu should be also without "the" and without "Taq". 